\title{
A simulation-based analysis for improvement of productivity in sick chemical dyeing factory: a research article
}

\author{
Annamalai Sivakumar* \\ Department of Mechanical Engineering, \\ Kongu Engineering College - Perundurai, \\ Erode: 638 052, Tamilnadu, India \\ E-mail: askmechkongu@gmail.com \\ *Corresponding author
}

\author{
Kaliannan Saravanan \\ Department of Chemical Engineering, \\ Kongu Engineering College - Perundurai, \\ Erode: 638 052, Tamilnadu, India \\ E-mail: rumisivaesh@yahoo.co.in
}

\begin{abstract}
This paper provides an overview of the various processes in textile fabric industry. From the analysis of data taken during the past three years, the company has noted that it has not achieved the targeted productivity. Total productive maintenance (TPM) has been a major component of improvement strategy to enhance the organisational productivity and profitability. Identification of resources and use resources play a critical role in any industry for the improvement of quality and productivity. For example, fabric industry could not get the determined productivity since TPM was not followed. The objective of this paper is to present the result of the past three years productivity data and discussed different results obtained after implementing the procedures of TPM in the failure textile industry. A systematic methodology is presented and analysed by software for improvement productivity at the factory level. Metrics of overall equipment effectiveness (OEE) is introduced and developed a structured robust framework for improvement of quality and productivity.
\end{abstract}

Keywords: productivity; fabric; textile; total productive maintenance; TPM; equipment effectiveness.

Reference to this paper should be made as follows: Sivakumar, A. and Saravanan, K. (2011) 'A simulation-based analysis for improvement of productivity in sick chemical dyeing factory: a research article', Int. J. Electronic Transport, Vol. 1, No. 1, pp.96-110.

Biographical notes: Annamalai Sivakumar is working as an Assistant Professor and Research Scholar in the Department of Mechanical Engineering in Kongu Engineering College, Perundurai, Tamilnadu, India. He earned his Bachelor of Engineering in Mechanical Engineering and Master of Engineering in Industrial Engineering from Bharathiar University, Coimbatore, India and Regional Engineering College, Tiruchirapalli, India, respectively. His current research relates in the area of TQM, TOC, TPM and supply chain management (SCM). 
Kaliannan Saravanan is a Professor in the Department of Chemical Engineering at Kongu Engineering College, Perundurai, Erode. He finished his $\mathrm{PhD}$ in Indian Institute of Technology, IIT Bombay, India. His primary interest is in the areas of design of management strategy, techniques in process industry, finding problems in failure industry, etc. He has published a number of papers in peer refereed journals.

\section{Introduction}

In this textile fabric industry, grey fabrics are converted into calendared product. Several sequential steps are including in good fabric preparation such as fabric preparation, desizing, scouring bleaching dyeing and calendaring. These operations are employed in dye houses according to customer requirements fabric preparation. Fabric preparation is a series of treatment steps to remove impurities that may interfere with the subsequent dyeing and finishing processes. The preparation treatments usually include desizing, scouring and bleaching, but may also include singeing (a dry process) and mercerising. From the analysis of data taken during the past three years, the company has noted that it has not achieved the targeted productivity. Less productivity caused heavier losses in the management. A team has been formed, analysed and noted that the factory has not followed any maintenance activities. Giegling et al. (1997) have implemented in industry. The work aims at studying industrial systems (textile fabric industry situated in Southern state in country) and its various subsystems, analysing the different failure and maintenance activities of the various constituents in the subsystems. Many successful applications are reported in Huang et al. (2003), Chand and Shirvani (2000), Green et al. (1997), Jonsson (1997), and Jostes and Helms (1994). Raouf (1994) said that how to improve the capital productivity in industry. Sherwin and Jonsson (1995) have pointed out the plant maintenance in industry. Subramanian et al. (2001).explained about the reducing and utilising down of machines in a simulation optimisation framework for research and development pipeline management.

\subsection{Processing machines in textile industry}

The following machines are used to convert the grey fabric into calendared product:

1 Jigger machines: In the simplest term, a jigger is a dyeing machine on which the fabric in flat form, after it passes through the dye bath, is batched as a roller. This process is repeated number of times as the fabric is batched from the one roller to the other. Each such pass is termed as 'end'. Figure 1(a) illustrates the photographic view of jigger machine.

2 Stenter machine: Cotton fabrics, after bleaching process, shrink widthwise and weft becomes distorted. The main function of the stenter is to stretch the fabric widthwise and to recover the uniform width. Figure 1(b) shows the view of stenter machine. The stenter machine is also used to dry the fabric, give heat setting to synthetics and blended fabrics, give soft finish, give curing treatment for some special finishes such as resin finishing, water repellent, etc., to the fabric and stretch the fabric to required width. 
Figure 1 Different processing machineries in textile fabric industry, (a) jigger machine (b) stenter machine (c) squeezing machine (d) calender machine

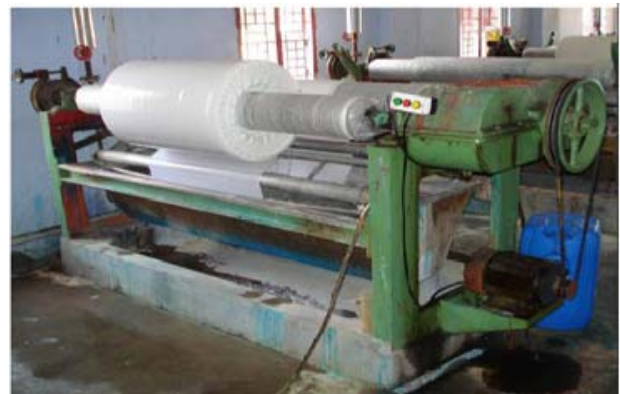

(a)

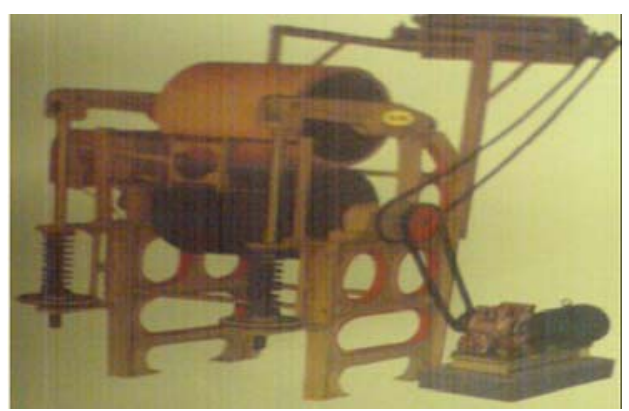

(c)

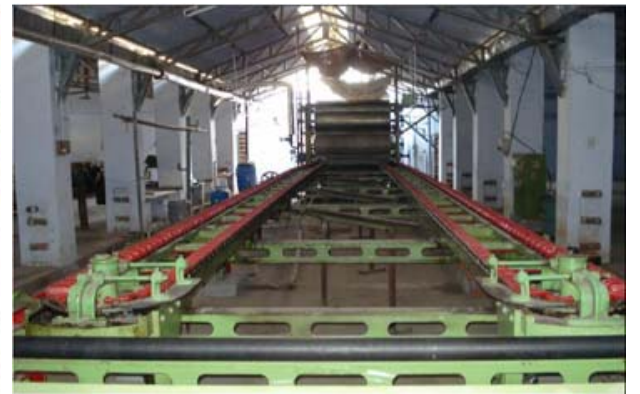

(b)

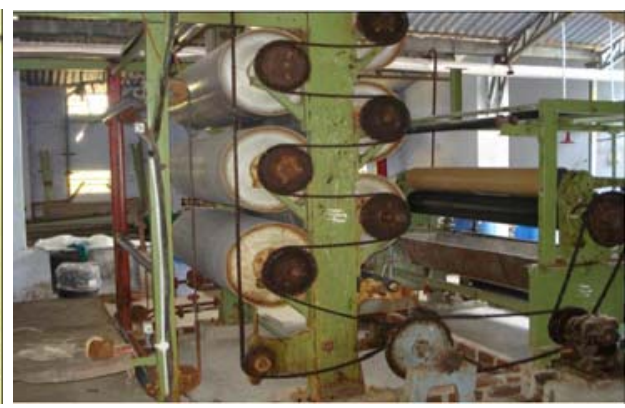

(d)

3 Squeezing machine: Heavy duty ebonite and rubber rolls are mounted on a well-machined CI side wall ensuring maximum squeezing of water. Adjustable mechanical spring loaded pressure system and AC driving device for machine and wooden top winch are also included. Figure 1(c) illustrates the squeezing machine in textile industry.

4 Calender machine: Seven bowl calender is one type of calender machine as shown in Figure 1(d). The calendaring effect produced depends on the moisture content of the fabric, the number of bowls used in the calendar, the composition of the bowls, the arrangement of the bowls, temperature, pressure, and speed of the machine. Generally, the compressed material bowls are made from either cotton or wool paper, linen paper or flax paper. The hard bowl is made up of either chilled iron or close grained cast iron or steel. Iron bowls are made with highly polished surface and are heated from inside by steam or gas. The fabric is passed through the machine in between the bowls and as the result gloss is developed in the calendared fabric. In this machine there are three iron bowls and four cotton bowls. In between two metallic bowls, one cotton bowl is arranged. Care should be taken in such a way that no two iron bowls are arranged together to avoid damage to the fabric. Sufficient pressure is employed by either weighing the rollers with heavy weights or by spring weighing or by hydraulic pressure weighing. Normal speed is 60 to 80 yards $/ \mathrm{min}$ and the normal pressure is 40 to 60 tons. After bleaching or dyeing or washing and after drying, the fabrics will have wrinkles and creases. To remove these wrinkles, the fabric is to be ironed to enable easy cutting. Technically, we call this ironing method 
as calendaring. This is done with steam pressure to get smooth, glossy finish of fabric. Also, this will help the fabric to maintain its diameter.

\section{Background for the research}

Many manufacturing systems operate at a lower capacity with a consequence of a higher cost of the producing products. In the fabric dyeing process industry, the production process requires non-stop operation of automatic production line equipment. A stoppage in a production line, due to a failure of the equipment, causes a drop in the production rate and quality problems on the products. Low productivity is the result of the worst function of the production lines. This is can be a result of imperfect maintenance of the machines. Maintenance is undertaken to preserve the proper function of the system so that it will continue to do what it was designed to do. A success of the product is generally measured by satisfaction of the customer who seeks good quality. So, quality is the prime factor in the success of the product.

Failure of the product is mainly due to poor quality of the product is mainly due to poor quality of product and the downtime loss in fabric dyeing processing industry leads to the loss in availability of the equipment, in turn leads to the less overall equipment effectiveness (OEE). The downtime loss results in shut down of the particular equipment which decreases the OEE. This is considered to be the one of the major losses to the company. So it becomes to reduce the downtime loss in order to increase the productivity of the particular equipment. There are various mathematical models for measuring OEE developed by various researchers. Baesler et al. (2002), Hernandez-Matias et al. (2006), EIMekkawy et al. (2006) and Chandra and Kumar (2000) have defined OEE in combination with operation, maintenance and management of manufacturing equipment and resources. Muthiah and Huang (2007) present some practical solutions highlighting the OEE teams at the Texas Instruments, USA which have been designed to minimise many of the semiconductor metric problems. Rathore et al. (2005) investigated OEE data with a productivity analysis framework called capacity utilisation bottleneck efficiency system, which identified and prioritised productivity inefficiencies with the decreasing in their accompanying tool capacity. Mohanta (2010) has stated about the various techniques of productivity improvement tools.

However, in our literature survey (Reid, 2006; Huang et al., 2002; Vijayaram et al., 2006), we have found any instance of OEE improvement through the use of techniques like abnormality identification sheet and why-why analysis. It inspires to implement the total productive maintenance (TPM) procedures in textile sick industry.

\section{Research objectives and methodologies}

Quality of the products and production rate can be increased by implementing engineering techniques. Hence, sick fabric dyeing process industry is taken and analysed every corner reasons for low productivity. The methodology is based on analysing the previous production data of manual and automatic production line. Method is divided into various steps, whose aims are bring forth improved maintenance policies of the mechanical equipment. Also, the continuous and through inspection of the production 
process is achieved through measurements of the OEE. The goal of the development methodology is to bring the competitive advantages, such as increasing the productivity, improving the quality of the products and project gives an idea about outcomes of industry such as productivity, quality, profit, etc., by introducing a new framework. Figure 2 illustrates the graphs of the production loss in various processing machines for the year 2007, 2008 and 2009 taken from industry. According to coefficient of variation, jigger machines and stenter machine were given low productivity in the year 2007and 2009, respectively, whereas squeezing machine and calendar machine were in the year 2008. Finally, guidelines are suggested and implemented by way of the framework; so that the systemic effects of changes are identified from existing way of work. Its result is used to improve the important systems and subsystems of machineries. Figure 3 illustrates an autonomous system of maintenance before and after implementing TPM. Felix and Riggs (1983) paper suggested that collecting procedures of productivity measurements data. Koljonen and Reid (2000) and Reid (2002) papers have given excellent idea about constraint framework in a service organisation.

Figure 2 (a) Percentage of production loss in every year for jigger machines (b) percentage of production loss in every year for stenter machine (c) percentage of production loss in every year for squeezing machine (d) percentage of production loss in every year for calendar machine

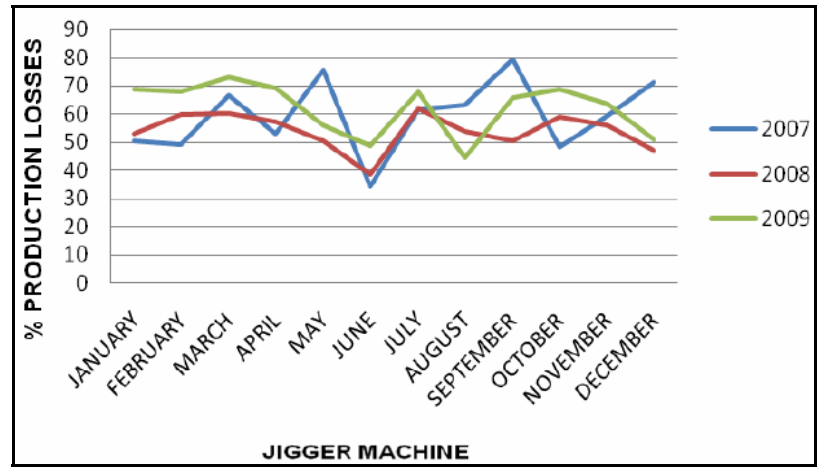

(a)

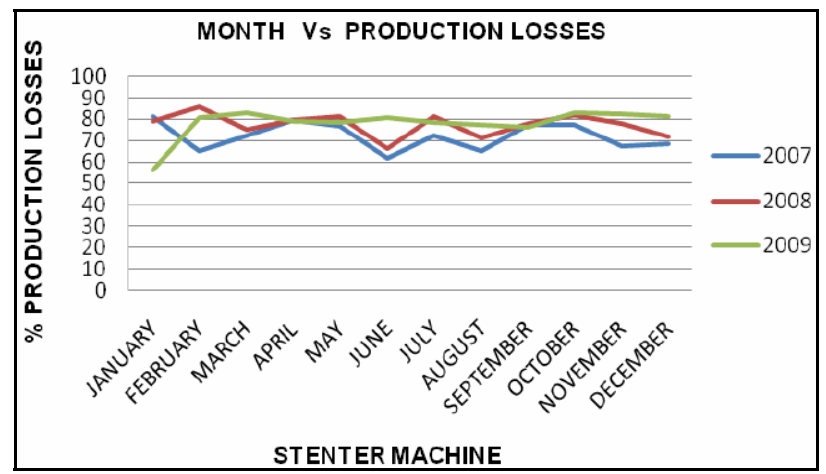

(b) 
Figure 2 (a) Percentage of production loss in every year for jigger machines (b) percentage of production loss in every year for stenter machine (c) percentage of production loss in every year for squeezing machine (d) percentage of production loss in every year for calendar machine (continued)

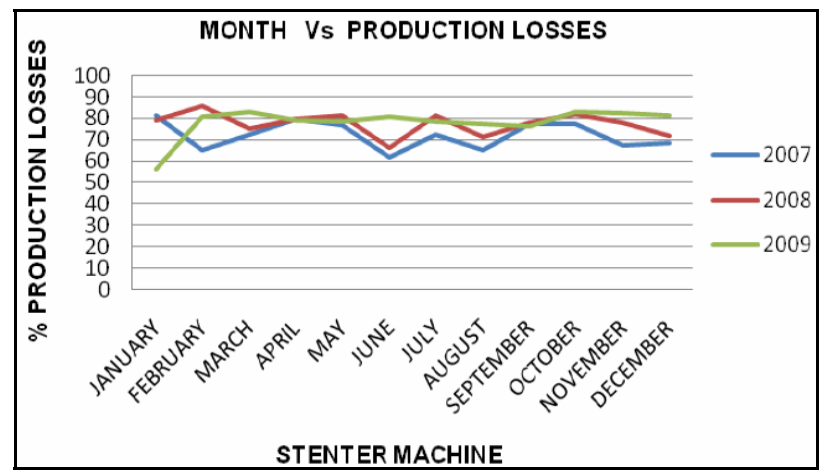

(c)

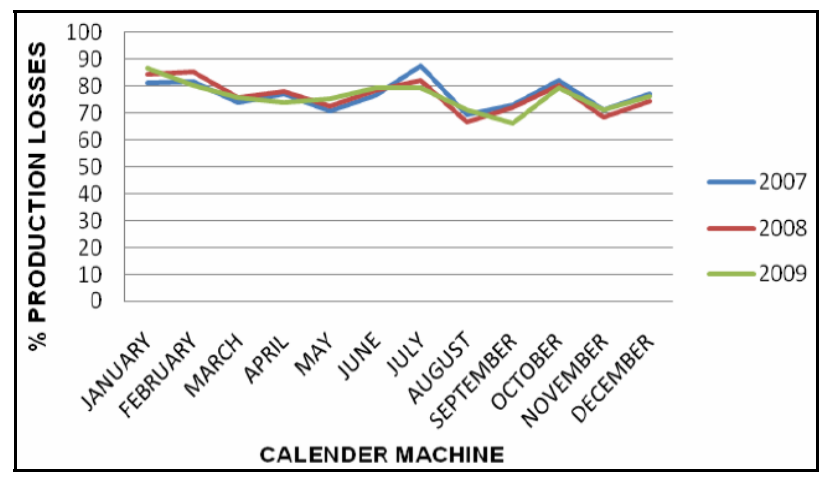

(d)

\section{Existing framework of an industry before TPM and performance of machines}

Figures 3 and 4 illustrate the block diagram of existing framework of an industry before TPM and comparison of OEE performance of all processing machines. This diagram simply consist of breakdown maintenance (BM), poor plant layout poor resources and improper allocation of worker and past production data were taken in existing framework. This framework is unstructured and improper. Table 1 represents the allocation of man power for maintenance before implementing TPM. Various results, graphs and procedures are obtained for different machineries after implementing TPM procedures. 
Figure 3 Existing unstructured framework of factory before TPM

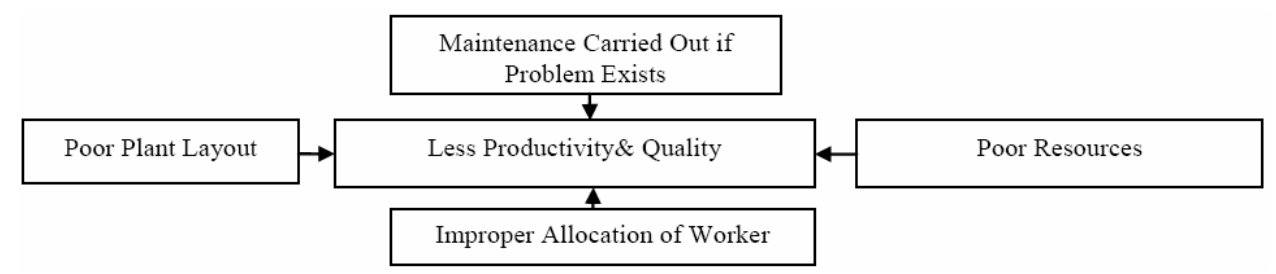

Figure 4 Comparisons between OEE of all processing machines with world class OEE

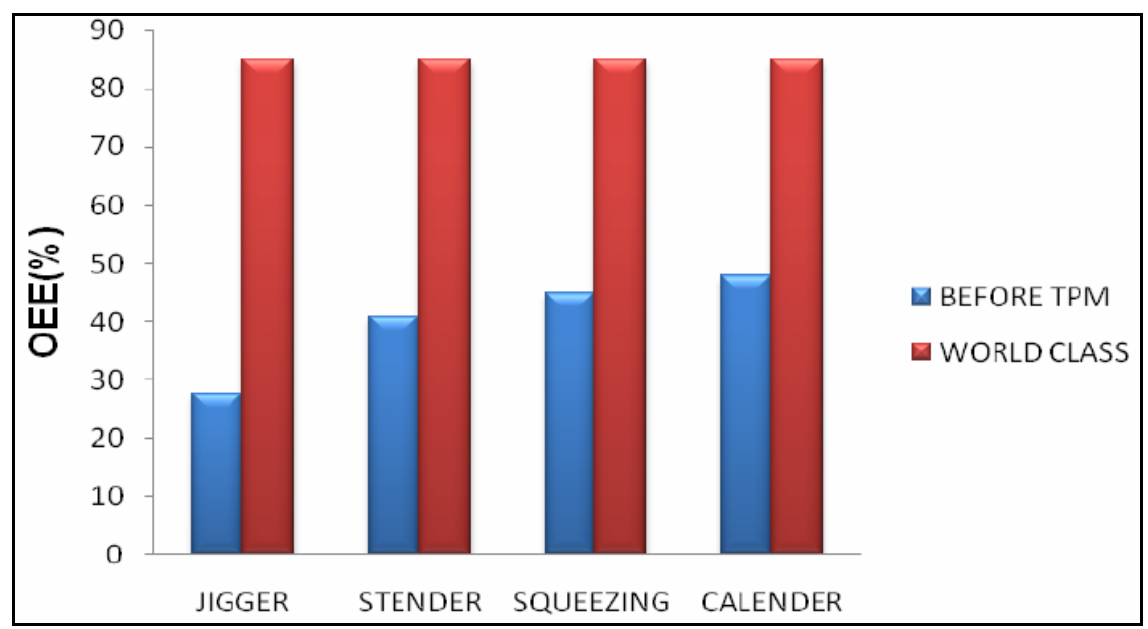

Table 1 Allocation of resources in industry

\begin{tabular}{|c|c|c|c|c|}
\hline \multirow{2}{*}{ Activities } & \multicolumn{2}{|c|}{ Before implementing TPM } & \multicolumn{2}{|c|}{ After implementing TPM } \\
\hline & Maintenance staff & Operators & Maintenance staff & Operators \\
\hline Production & No & Yes & Yes & Yes \\
\hline Setup and measurement & No & No & Yes & Yes \\
\hline Cleaning & No & Yes & Yes & Yes \\
\hline Lubrication & Yes & No & Yes & Yes \\
\hline Periodic maintenance & No & No & Yes & Yes \\
\hline Corrective maintenance & Yes & No & Yes & Yes \\
\hline Break down maintenance & Yes & Yes & Yes & Yes \\
\hline Predictive maintenance & No & No & Yes & Yes \\
\hline Adding chemicals & No & Yes & Yes & Yes \\
\hline $\begin{array}{l}\text { Thermal maintenance or } \\
\text { boiler maintenance }\end{array}$ & Yes & No & Yes & Yes \\
\hline Preventive maintenance & No & No & Yes & Yes \\
\hline
\end{tabular}




\section{Robust framework of an industry before TPM and performance of machines}

Figure 5 illustrates the robust framework which is implemented in textile fabric industry. The gap between productivity and quality performance has been analysed in this framework. Target has to be planned and implement based on goal. Resources are to be analysed before implementing any activities. First, the design should determine the production parameters with reference existing resources.

Figure 5 A robust framework for productivity improvement

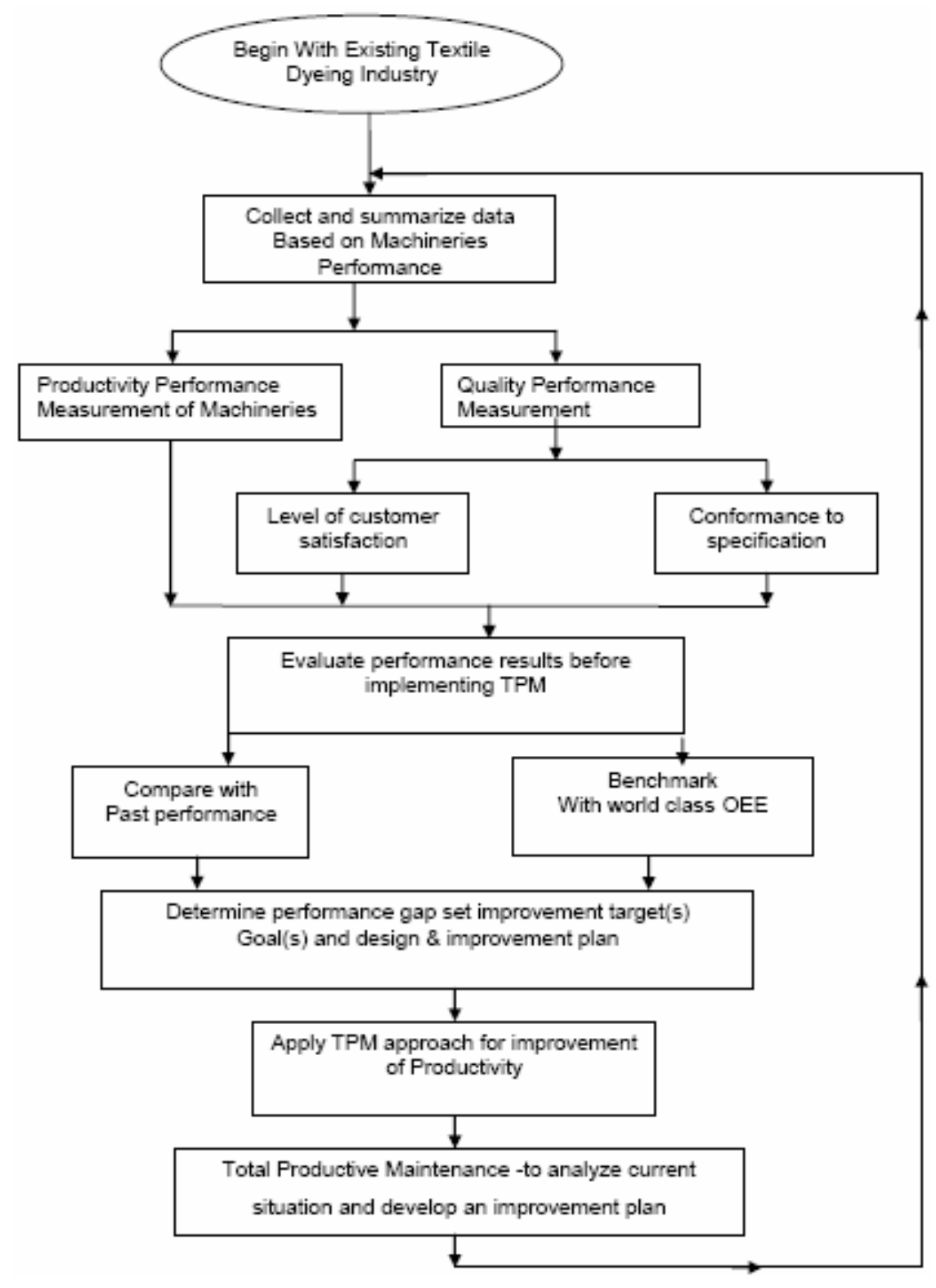




\subsection{Planned maintenance}

Planned maintenance is the specialised maintenance carried out by the maintenance department. Planned maintenance needs the support of the autonomous maintenance by manufacturing department. The goals of planned maintenance are to eliminate equipment failures and process problems and minimise losses. An efficient planned maintenance programme combines time-based maintenance (TBM), corrective maintenance (CM) and $\mathrm{BM}$ as rationally as possible. The various systems and subsystems of textile processing machineries are scheduled according to the different types of maintenance.

\subsection{Optimised data for production}

Shift length: $\quad 8$ hours $=480$ minutes

Short breaks: 2 breaks $@ 15$ minutes each = 30 minutes

Total meal break: 1 breaks @60 minutes each=60 minutes

Total down time: 45 minutes

Ideal run rate: $\quad 2 \mathrm{~m} /$ minute

Total fabrics: $\quad 500 \mathrm{~m}$

Reject fabrics: $15 \mathrm{~m}$

\section{3}

\begin{tabular}{lcc}
\hline Support variable & Calculation & Result \\
\hline Planned production time & Shift length - breaks & 390 minutes \\
Operating time & Planned production time - down time & 345 minutes \\
Good fabrics & Total fabrics - reject fabrics & $485 \mathrm{~m}$ \\
\hline
\end{tabular}

\section{Results, discussion and conclusions}

OEE is calculated by multiplying machine availability, performance and quality. These three major parameters play a critical role of production result can be seen from Table 4 for all fabric machines of OEE. Table 2 illustrates the average OEE for jigger machines. This average OEE is calculated on daily basis production rate for every week in all 12 jigger machine. Similarly, various improved results are viewed from stentre, calendaring and squeezing machines. The average performances of these processing machines are illustrated in Figure 8. The production parameters and sequences of operations have been changed from unstructured framework. The total fabric rejection is greatly reduced by implementing maintenance steps for all machineries. Here, result is observed that the OEE before implementing TPM is lesser than present result of OEE. This seven month readings are observed from various machines through utilisation of different resources after implementing TPM. The system of fabric machines are sequenced such as s system, subsystem, effect, causes, remedies and maintenance schedule of production line. Cost of every activity is assumed as negligible. High percentage of improvement result could be 
seen from Table 3. It gives good satisfaction to customer, management and workers. Figures 8 and 9 give the average OEE for all machines for a week and average OEE performance of fabric machines, respectively. OEE factors of each machine are calculated and compared with world class OEE (85\%) for after implementing TPM results are taken software as shown in Figure 6 which give various improvement while changing the factory layout.

Figure 6 Software results of steps of dyeing module

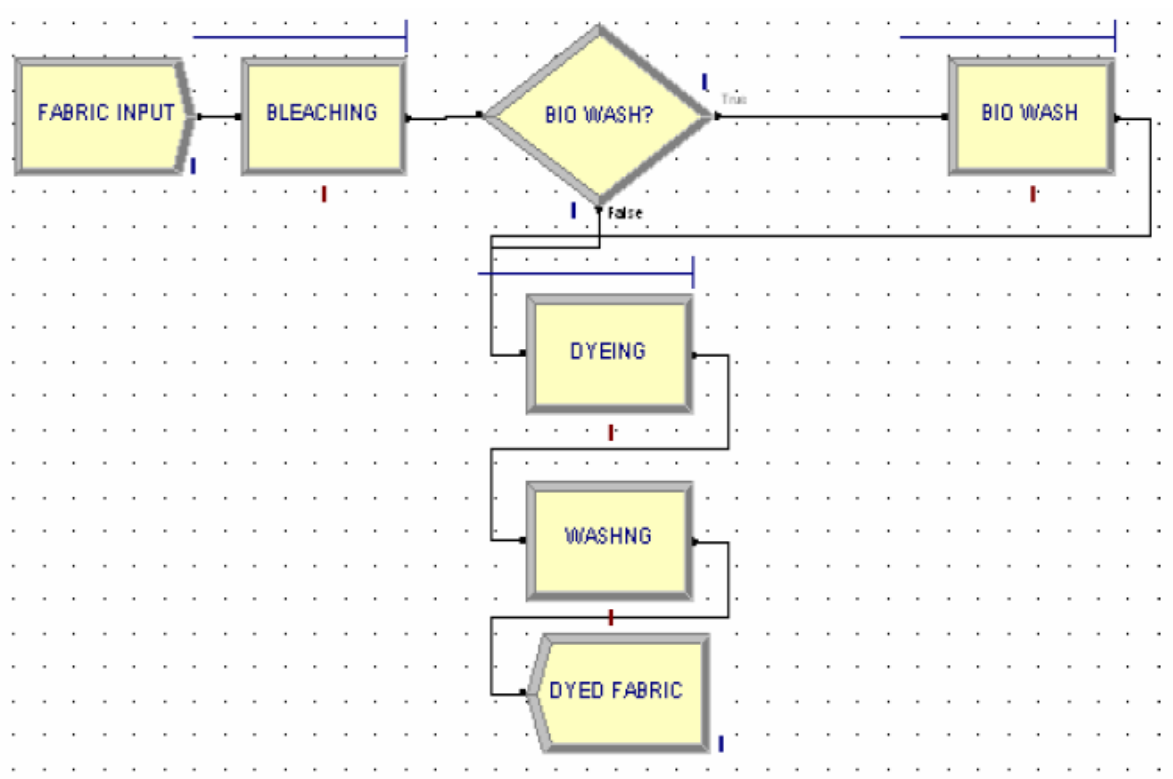

Figure 7 Comparison of average OEE including world leaders after implementing TPM

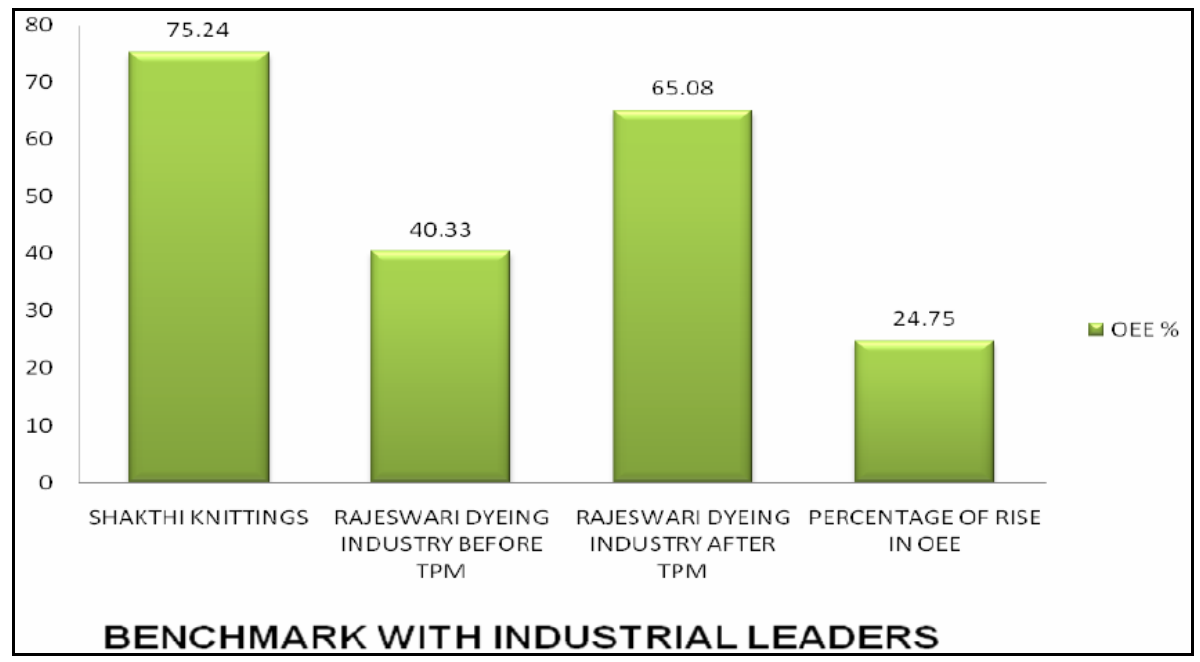


Table 2 Average OEE for jigger machines (e.g.)

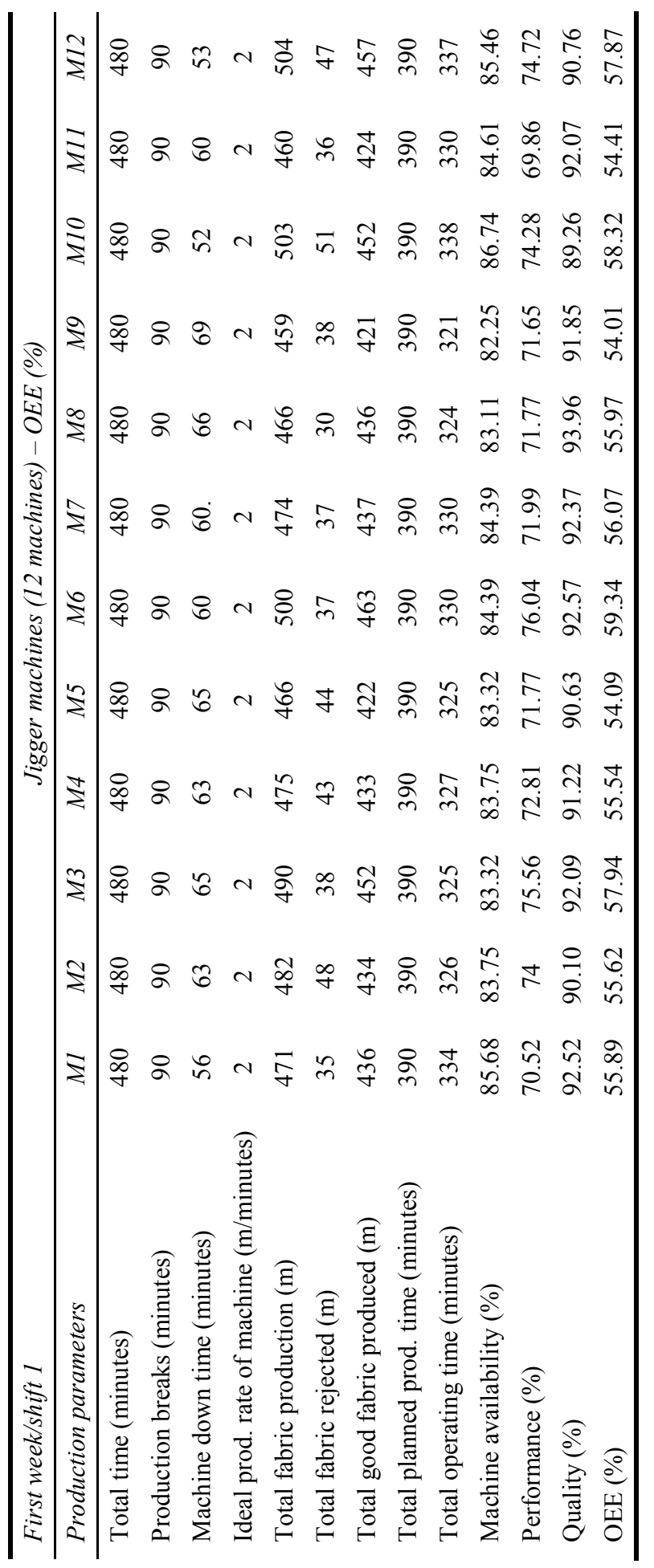


Table 3 Average OEE for all machines after implementing TPM

\begin{tabular}{lcccc}
\hline \multirow{2}{*}{ Parameters (\%) } & \multicolumn{4}{c}{ Type of machines } \\
\cline { 2 - 5 } & Jigger & Stenter & Squeezing & Calender \\
\hline Availability & 84.23 & 86.10 & 86.53 & 86.3 \\
Performance & 72.91 & 76.01 & 82.72 & 81.60 \\
Quality & 91.61 & 98.62 & 98.22 & 98.45 \\
OEE & 56.25 & 64.48 & 70.35 & 69.24 \\
\hline
\end{tabular}

Table 4 OEE for all processing machines after implementing TPM

\begin{tabular}{|c|c|c|c|c|c|c|c|}
\hline Machines & Production parameters & Day 1 & Day 2 & Day 3 & Day 4 & Day 5 & Day 6 \\
\hline \multirow{13}{*}{$\begin{array}{l}\text { Stenter } \\
\text { machine }\end{array}$} & Total time (minutes) & 480 & 480 & 480 & 480 & 480 & 480 \\
\hline & Production breaks (minutes) & 90 & 90 & 90 & 90 & 90 & 90 \\
\hline & Machine down time (minutes) & 50 & 55 & 50 & 60 & 45 & 65 \\
\hline & $\begin{array}{l}\text { Ideal production rate of } \\
\text { machine }(\mathrm{m} / \text { minutes })\end{array}$ & 75 & 75 & 75 & 75 & 75 & 75 \\
\hline & Total fabric production (m) & 22,000 & 18,000 & 17,800 & 19,000 & 18,000 & 20,000 \\
\hline & Total fabric rejected (m) & 570 & 160 & 102 & 150 & 300 & 350 \\
\hline & $\begin{array}{l}\text { Total good fabric produced } \\
\text { (m) }\end{array}$ & 21,430 & 17,840 & 17,698 & 18,850 & 17,700 & 19,650 \\
\hline & $\begin{array}{l}\text { Total planned production time } \\
\text { (minutes) }\end{array}$ & 390 & 390 & 390 & 390 & 390 & 390 \\
\hline & Total operating time (minutes) & 340 & 335 & 340 & 330 & 345 & 325 \\
\hline & Machine availability (\%) & 87.17 & 85.89 & 87.17 & 84.61 & 88.46 & 83.33 \\
\hline & Performance (\%) & 86.27 & 71.64 & 69.8 & 76.76 & 69.56 & 82.05 \\
\hline & Quality (\%) & 97.4 & 99.11 & 99.42 & 99.21 & 98.33 & 98.25 \\
\hline & OEE $(\%)$ & 73.24 & 60.98 & 60.49 & 64.43 & 60.62 & 67.17 \\
\hline \multirow{13}{*}{$\begin{array}{l}\text { Squeezing } \\
\text { machine }\end{array}$} & Total time (minutes) & 480 & 480 & 480 & 480 & 480 & 480 \\
\hline & Production breaks (minutes) & 90 & 90 & 90 & 90 & 90 & 90 \\
\hline & Machine down time (minutes) & 50 & 65 & 55 & 40 & 60 & 45 \\
\hline & $\begin{array}{l}\text { Ideal production rate of } \\
\text { machine }(\mathrm{m} / \text { minutes })\end{array}$ & 55 & 55 & 55 & 55 & 55 & 55 \\
\hline & Total fabric production (m) & 14,500 & 13,500 & 15,000 & 17,250 & 15,500 & 17,000 \\
\hline & Total fabric rejected (m) & 255 & 250 & 500 & 275 & 328 & 300 \\
\hline & $\begin{array}{l}\text { Total good fabric produced } \\
(\mathrm{m})\end{array}$ & 14,245 & 13,250 & 14,500 & 16,975 & 15,172 & 16,700 \\
\hline & $\begin{array}{l}\text { Total planned production time } \\
\text { (minutes) }\end{array}$ & 390 & 390 & 390 & 390 & 390 & 390 \\
\hline & Total operating time (minutes) & 340 & 325 & 335 & 350 & 330 & 345 \\
\hline & Machine availability (\%) & 87.17 & 83.33 & 85.89 & 89.74 & 84.61 & 88.46 \\
\hline & Performance (\%) & 77.54 & 75.52 & 78.69 & 89.61 & 85.39 & 89.59 \\
\hline & Quality (\%) & 98.24 & 98.14 & 98.46 & 98.4 & 97.88 & 98.23 \\
\hline & OEE $(\%)$ & 66.4 & 61.73 & 66.54 & 79.12 & 70.71 & 77.84 \\
\hline
\end{tabular}


Table 4 OEE for all processing machines after implementing TPM (continued)

\begin{tabular}{llcccccc}
\hline Machines & \multicolumn{1}{c}{ Production parameters } & Day 1 & Day 2 & Day 3 & Day 4 & Day 5 & Day 6 \\
\hline Calender & Total time (minutes) & 480 & 480 & 480 & 480 & 480 & 480 \\
machine & Production breaks (minutes) & 90 & 90 & 90 & 90 & 90 & 90 \\
& Machine down time (minutes) & 45 & 50 & 40 & 60 & 55 & 50 \\
& Ideal production rate of & 70 & 70 & 70 & 70 & 70 & 70 \\
& machine (m/minutes) & & & & & & \\
& Total fabric production (m) & 18,500 & 20,000 & 19,000 & 18,000 & 20,000 & 21,000 \\
& Total fabric rejected (m) & 250 & 355 & 250 & 200 & 300 & 375 \\
& Total good fabric produced & 18,250 & 19,645 & 18,750 & 17,800 & 19,700 & 20,625 \\
& (m) & & & & & & \\
& Total planned production time & 390 & 390 & 390 & 390 & 390 & 390 \\
& (minutes) & & & & & & \\
& Total operating time (minutes) & 345 & 340 & 350 & 330 & 335 & 340 \\
& Machine availability (\%) & 88.46 & 87.17 & 89.74 & 84.61 & 85.89 & 81.93 \\
& Performance (\%) & 76.6 & 84.03 & 77.55 & 77.92 & 85.28 & 88.23 \\
& Quality (\%) & 98.64 & 98.22 & 98.68 & 98.88 & 98.12 & 98.21 \\
& OEE (\%) & 66.83 & 71.94 & 68.67 & 65.19 & 71.86 & 70.99 \\
\hline
\end{tabular}

Figures 8 and 9 Performance of OEE after implementing TPM in textile dyeing machines and comparisons between OEE with world class for all machines after implementing TPM, respectively

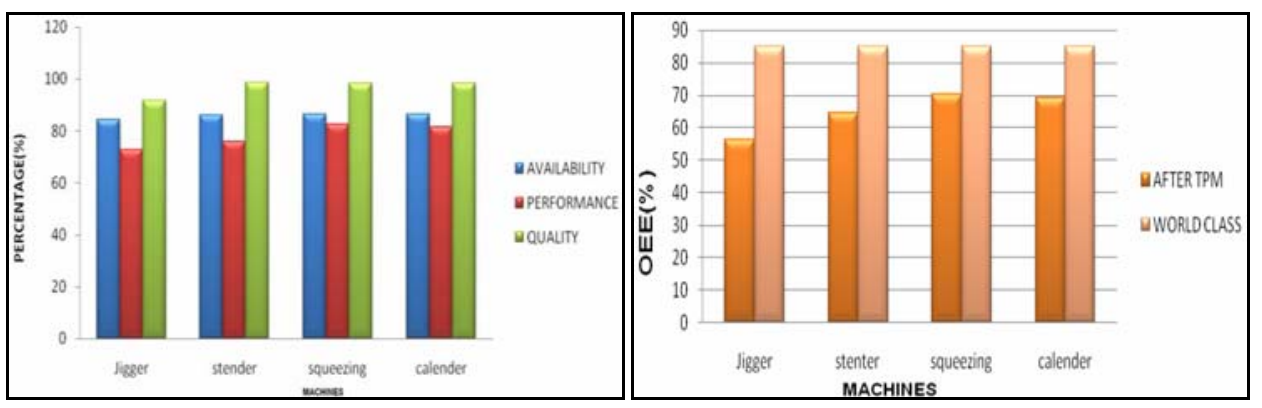

Thus, the quality and productivity of the product is increased by implementing TPM. The planned maintenance of the textile processing machines is increased through which the quality products are produced. Also, by reducing the downtime and increasing the production of the machine/minutes which increases the OEE by $25 \%$. So, the productivity of the product is increased by increasing the OEE. Thus, the TPM technique is effectively used for increasing the productivity. The firm gets success in terms of profit by compensating the problem of quality and productivity. The developed methodology has an aim to bring, concerning the creation of competitive advantages, exploitation increase of mechanical equipment of an industry. Figure 9 illustrates result and comparison with world class benchmark. The following suggestions are listed after implementing TPM in sick fabric industry: 
- $\quad$ increases of production by maximise the equipment utilisation ( $20 \%$ less from benchmark OEE)

- $\quad$ product quality improvement via the quality rate of the equipment

- improvement planned maintenance of the equipment (25\% improved after TPM)

- weak points will be revealed and priorities in the equipment of corrective actions will be given

- economy in natural resources and energy, via the reduction of downtimes, the total process time as well as the maximise the equipment utilisation by TPM approach.

The OEE was calculated for few months after implementation of TPM. This may be referred as limitations. Fuzzy maintenance schedule may be incorporated as future scope in this paper.

\section{References}

Baesler, F.F., Moraga, M. and Ramis, F.J. (2002) 'Productivity improvement in the wood industry using simulation and artificial intelligence', Winter Simulation Conference, pp.1095-1098.

Chand, G. and Shirvani, B. (2000) 'Implementation of TPM in cellular manufacture', Journal of Materials Processing Technology, Vol. 103, pp.144-154.

Chandra, C. and Kumar, S. (2000) 'An application of a system analysis methodology to manage logistics in a textile supply chain', International Journal of Supply Chain Management, Vol. 5, pp.234-244.

EIMekkawy, T.Y., Hachkowski, P.A., Strong, D. and Mann, D.D. (2006) 'Defect analysis for quality and productivity improvements in a manufacturing system', Canadian Biosystems Engineering, Vol. 48, pp.7.9-7.12.

Felix, G.H. and Riggs, J.C. (1983) 'Productivity measurements by objectives', National Productivity Review, Autumn, Vol. 2, No. 4, pp.386-393.

Giegling, S., Verdini, W.A., Haymon, T. and Konopka, J.M. (1997) 'Implementation of overall equipment effectiveness (OEE) system at a semiconductor manufacturer', Proceedings of 1997 IEMT Symposium, Austin, TX.

Green, T.B., Newsom, W.B. and Jones, S.R. (1977) 'A survey of the applications of quantitative techniques to production/operations management in large corporations', Academy of Management Journal, Vol. 20, No. 4, pp.669-676.

Hernandez-Matias, J.C., Vizan, A., Hidalgo, A. and Rios, J. (2006) 'Evaluation of techniques for manufacturing process analysis', International Journal of Manufacturing Technology, Vol. 17, pp.571-583.

Huang, S.H., Dismukes, J.P., Su, Q., Wang, G. and Rauak, M.A. (2002) 'Manufacturing system modeling for productivity improvement', Journal of Manufacturing System, Vol. 21, No. 4.

Huangt, S.H., Dismukes, J.P., Shit, J., Su, Q., Razzak, M.A., Bodhale, R. and Robinson, D.E. (2003) 'Manufacturing productivity improvement using effectiveness metric and simulation analysis', International Journal of Production, Vol. 41, No. 3, pp.513-527.

Jonsson, P. (1997) 'The status of maintenance management in Swedish manufacturing firms', Journal of Quality Maintenance Engineering, Vol. 3, No. 4, pp.233-258.

Jostes, R.S. and Helms, M.M. (1994) 'Total productive maintenance and its link to total quality management', Work Study, Vol. 43, No. 7, pp.18-20.

Koljonen, E.L. and Reid, R.A. (2000) 'Applying the three Ps constraint framework in a service organization', Constraint Management Symposium Proceedings, pp.91-96, APICS, Alexandria, VA. 
Mohanta, G.C. (2010) 'Perception of top level management workers on productivity improvement through tools and techniques', Journal of Management Research, Vol. 2, No. 1, pp.1-18.

Muthiah, K.M.N. and Huang, S.H. (2007) 'Overall throughput effectiveness (OTE) metric for factory level performance monitoring and bottleneck detection', International Journal of Production Research, Vol. 45, No. 20, pp.4753-4769.

Raouf, A. (1994) 'Improving capital productivity through maintenance', Int. J. of Operation Production Management, Vol. 14, No. 7, pp.44-52.

Rathore, A., Mohanty, R.P., Lyons, A.C. and Barlow, N. (2005) 'Performance management through strategic total productive optimization', International Journal of Advance Manufacturing Technology, Vol. 25, pp.1020-1028.

Reid, R.A. (2002) 'An integrated operations performance metric', Quality Progress, Vol. 35, pp.51-55.

Reid, R.A. (2006) 'Productivity and quality improvement: an implementation framework', International Journal of Productivity and Quality Management, Vol. 1, pp.26-36.

Sherwin, D.J. and Jonsson, P. (1995) 'TQM - maintenance and plant availability', Journal of Quality Maintenance Engineering, Vol. 1, No. 1, pp.15-19.

Subramanian, D., Pekny, J.F. and Reklaitis, G.V. (2001) A simulation optimization framework for research and development pipeline management', AIChE Journal, Vol. 47, pp.2226-2242.

Vijayaram, T.R., Sulaiman, S. and Ahmad, M.H.M. (2006) 'Foundry quality control aspects and prospects to reduce scrap rework and rejection in metal casting manufacturing industries', Journal of Materials Processing Technology, Vol. 178, pp.39-43. 